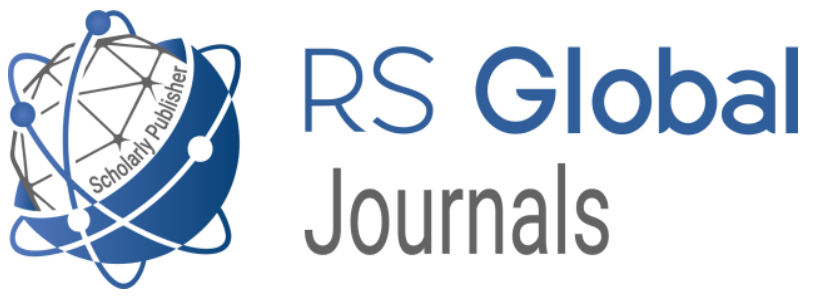

Scholarly Publisher

RS Global Sp. z O.O.

ISNI: 0000000484952390

Dolna 17, Warsaw, Poland 00-773

Tel: +48226022703

Email: editorial_office@rsglobal.pl

JOURNAL International Journal of Innovative Technologies in Social Science

p-ISSN 2544-9338

e-ISSN 2544-9435

PUBLISHER RS Global Sp. z O.O., Poland

ARTICLE TITLE PЕСУРСОВ КАЗАХСТАНА НА ОСНОВЕ ЦЕЛЕВОЙ ФУНКЦИИ

Павличенко Л. М.,

AUTHOR(S) Байбосунова Г. Е.,

Рысмагамбетова А. А.,

Pavlichenko L. M., Baibosunova G. Ye., Rysmagambetova A. A. (2021) Comprehensive Assessment of Agroclimatic Resources of

ARTICLE INFO Kazakhstan Based on a Target Function. International Journal of Innovative Technologies in Social Science. 2(30). doi:

10.31435/rsglobal_ijitss/30062021/7559

DOI

https://doi.org/10.31435/rsglobal_ijitss/30062021/7559

RECEIVED

28 April 2021

ACCEPTED

31 May 2021

PUBLISHED

04 June 2021

LICENSE

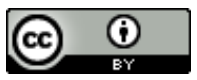

This work is licensed under a Creative Commons Attribution

4.0 International License.

(C) The author(s) 2021. This publication is an open access article. 


\title{
КОМПЛЕКСНАЯ ОЦЕНКА АГРОКЛИМАТИЧЕСКИХ РЕСУРСОВ КАЗАХСТАНА НА ОСНОВЕ ЦЕЛЕВОЙ ФУНКЦИИ
}

\author{
Павличенко Л. М., д.г.н., профессор, Казахский национальный университет имени аль-Фараби, \\ Алматы, Казахстан \\ Байбосунова Г. Е., магистрант, Казахский национальный университет имени аль-Фараби, \\ Алматы, Казахстан \\ Рысмагамбетова A. A., PhD доктор, старший преподаватель, Казахский начиональный \\ университет имени аль-Фараби, Алматы, Казахстан
}

DOI: https://doi.org/10.31435/rsglobal_ijitss/30062021/7559

\section{ARTICLE INFO}

Received 28 April 2021

Accepted 31 May 2021

Published 04 June 2021

\section{KEYWORDS}

objective function model, justification of assessment scales, territorial differentiation agroclimatic potential.

\begin{abstract}
The scientific works on agroclimatic zoning and assessments of the bioclimatic potential of the territory are widely represented in agroclimatology. Almost all of them are based on semi-empirical equations and formulas of various indices for calculating agroclimatic parameters. The work's purpose is an attempt to construct a comprehensive assessment of agroclimatic resources based on a theoretical mathematical model of the objective function and a scheme for its differentiation across the territory of Kazakhstan. The most frequently considered spring wheat in works on agroclimatology was chosen as the object of the study. The initial factual material is maps from the National Atlas of the Republic of Kazakhstan. To convert the cartographic information into quantitative, the method of constructing grid models of the selected maps was used with the subsequent determination of the quantitative initial values of the parameters in the centers of the blocks. The paper describes in detail the methodology for constructing rating scales for converting the values of parameters with different units of measurement into comparable scores, which were used to calculate the values of the partial and integral objective functions. The visualization of the results of calculating the integral objective function for the territory of Kazakhstan confirmed the correctness of the distribution over the territory of the previously identified zones of favorableness's different levels for the spring wheat cultivation, and therefore the possibility of using the objective function model for a comprehensive assessment of the territory agroclimatic potential.
\end{abstract}

Citation: Pavlichenko L. M., Baibosunova G. Ye., Rysmagambetova A. A. (2021) Comprehensive Assessment of Agroclimatic Resources of Kazakhstan Based on a Target Function. International Journal of Innovative Technologies in Social Science. 2(30). doi: 10.31435/rsglobal_ijitss/30062021/7559

Copyright: (C) 2021 Pavlichenko L. M., Baibosunova G. Ye., Rysmagambetova A. A. This is an openaccess article distributed under the terms of the Creative Commons Attribution License (CC BY). The use, distribution or reproduction in other forums is permitted, provided the original author(s) or licensor are credited and that the original publication in this journal is cited, in accordance with accepted academic practice. No use, distribution or reproduction is permitted which does not comply with these terms.

Введение. Сельскохозяйственное производство является важным фактором развития каждого региона, обеспечивающим как уровень его экономики, так и качество жизни населения. Под агроклиматическими ресурсами понимают совокупность климатических факторов и, в первую очередь, тепла и влаги, которые определяют условия производства и продуктивность сельскохозяйственных культур. Другими словами, это совокупность факторов, которые определяют, можно ли выращивать на исследуемой территории те или иные культуры, каковы будут их урожайность и трудоемкость агротехнологий $[1,2]$

В [3] отмечается, что «...оценка климата как ресурса для развития сельского хозяйства базируется на характеристиках термических ресурсов вегетационного периода, ресурсов влаги, условий зимнего периода. Кроме того, при агроклиматической оценке учитывают: 
- закон минимума (закон лимитирующего фактора), который гласит, что продуктивность (урожайность) определяется тем фактором, который находится в минимуме и

- количественные параметры связи продуктивности растений с факторами климата.

Сопоставляя климатические характеристики с потребностью сельскохозяйственных культур в тепле, влаге, а также с критическими температурами гибели растений, определяют степень соответствия агроклиматических ресурсов данной территории требованиям сельскохозяйственных культур, т.е. оценивают агроклиматический потенциал региона».

Учебные пособия по климатологии обращают внимание на сложность задачи исследований климатических ресурсов применительно к разным аспектам сельскохозяйственного производства, так как все компоненты, входящие в нее (живые объекты и климат), характеризуются большой изменчивостью $[4,5]$.

Краткое описание этих факторов применительно к Казахстану можно найти в [6]: «Территория Казахстана находится очень далеко от океана и открыта для ветров с запада и севера. Из-за этого основными свойствами климата Казахстана являются его резкая континентальность и неравномерное распределение природных осадков.

Зима в Казахстане холодная и продолжительная на севере и умеренно мягкая на юге. Средняя температура января варьирует от $-18^{\circ} \mathrm{C}$ на севере до $-3^{\circ} \mathrm{C}$ на юге. Лето - сухое. На севере - тёплое, в центре - очень тёплое, на юге - жаркое.

Атмосферные осадки незначительны, за исключением горных регионов.

Почти для всей территории Казахстана характерны сильные ветры, в ряде регионов свыше $40 \mathrm{~m} /$ сек. Рельеф местности Казахстана разнообразен. 58\% территории занимают пустыни и полупустыни, 10\% — горы. На севере республики преобладают степи и лесостепи. 23\% территории страны пригодны для земледелия, 70\% — для отгонного животноводства.

На северо-западе находится Предуральское плато. На западе страны лежит Прикаспийская низменность. На юго-западе — полуостров Мангышлак (Мангыстау). Восточнее расположено плато Устюрт. На северо-востоке от Каспийской низменности расположены Мугоджары, далее Тургайское плато. Возле Аральского моря находятся пустыня Кызылкум и песчаные массивы Большие Барсуки, Малые Барсуки и Приаральские Каракумы.

Центральную часть Казахстана занимает Центрально-Казахстанский мелкосопочник (Сары Арка) с его жемчужиной Каркаралинским Природоохранным парком в Карагандинской области. Южнее расположена пустыня Бетпак-Дала (Голодная степь), к югу от неё находится пустыня Моинкум, к востоку -Балхашская впадина. На юге находится Илийская впадина.

Самая низкая точка Казахстана — впадина Каракия на полуострове Мангыстау — 132 метра ниже уровня мирового океана. Самая высокая — пик Хан-Тенгри - 6995 м».

Итак, климат Республики вследствие удаленности от океанов отличается резкой континентальностью, когда наблюдается большая разница температур не только между сезонами года, но и в течение суток. Однако разнообразие рельефа и значительные размеры территории (по площади РК занимает девятое место в мире) обусловливает наличие различных климатических зон.

Краткая характеристика агроклиматических ресурсов представлена в [7]: «Разные регионы нашей страны обладают разными агроклиматическими ресурсами, но в целом на территории Казахстана солнечного тепла достаточно для созревания многих сельскохозяйственных культур. При среднесуточной температуре выше $+10^{\circ} \mathrm{C}$ его суммарное количество значительно колеблется: на севере $2000-2100^{\circ} \mathrm{C}$, а на юге $-4600-4800^{\circ} \mathrm{C}$.

В северной части Республики период превышения среднесуточных температур $+10^{\circ} \mathrm{C}$, длится 130-135 дней. Здесь агроклиматические ресурсы подходят для выращивания яровой пшеницы, льна, овощей, фруктов и бахчевых. В центральной части Казахстана климат относительно сухой. Ресурсы тепла - $2400^{\circ}-2800^{\circ} \mathrm{C}$. Количество дней, когда средняя температура поднимается выше $+10^{\circ} \mathrm{C}$, составляет $150-160$ дней. Здесь можно выращивать зерновые культуры, подсолнечник, гречиху и картофель. На юге республики вегетационный период длится немногим более 180 дней. Изобилие солнечного тепла позволяет выращивать здесь такие орошаемые культуры, как рис, хлопчатник, табак, виноград, сахарную свеклу и др.»

В первом разделе работы [8] «Методическая основа оценки агроклиматических ресурсов» рассматриваются методы оценки ресурсов различных климатических параметров и методики агроклиматического районирования и оценки биоклиматического потенциала 
территории. Практически все они построены на полуэмпирических уравнениях и формулах различных индексов для расчета агроклиматических параметров на основе мониторинговых данных по климатическим параметрам.

Целью нашей работы является попытка построения комплексной оценки агроклиматических ресурсов на основе теоретической математической модели целевой функции и схемы её дифференциации по территории Казахстана.

Поскольку специфика возделывания различных сельскохозяйственных культур значительно отличается по требованиям к климатическим параметрам, в качестве объекта построения целевых функций мы выбрали наиболее часто рассматриваемые в работах по агроклиматологии зерновые культуры, а конкретно - яровую пшеницу. Яровая пшеница - весенний сорт пшеницы, урожай которой поспевает в конце лета или начале осени. Яровой пшенице характерна стрессоустойчивость, она способна выжить в относительно засушливых условиях, однако наличие достаточного количества влаги в начале вегетации - обязательное условие. Потому яровая пшеница обычно выращивается там, где идут весенние и ранние летние дожди [9].

Материалы и методы. Исходным фактическим материалом нам послужили карты по разделу «Климат, агроклиматические ресурсы» из Национального Атласа Республики Казахстан [10]. Эти карты построены по среднемноголетним данным мониторинга климата. Выбор карт для построений осуществлялся в соответствии с рекомендациями в работах $[11,12]$.

При построении целевых функций климатических и агроклиматиеских параметров использовалось 8 карт из [10]: «Солнечное сияние. Год», «Осадки. Год», «Ветер. Год», «Число дней с пыльной бурей», «Продолжительность периода со средней суточной температурой воздуха выше $10^{\circ} \mathrm{C}$, «Сумма средних суточных температур воздуха выше $10^{\circ} »$, «Осадки за теплый период (апрель-октябрь)» и «Атмосферная засуха (апрель-октябрь)» Первые 4 карты характеризуют среднегодовые, остальные - агроклиматические параметры, которые используются для оценки выращивания сельскохозяйственных культур. В своей работе мы использовали эти карты для оценки благоприятности территории Казахстана для возделывания яровой пшеницы.

Для обеспечения возможности построения многомерной экспертно-статистической модели целевой функции использовался метод построения сеточных моделей выбранных карт с целью перевода картографической информации в количественную. Описания метода построения сеточных моделей территорий и способа построения целевых функций приводятся в монографии [13].

Первым этапом построения целевых функций является формирование базы количественных данных на основе исходной картографической информации. Преобразование картографической информации в количественную осуществлялось методом построения сеточной модели территории Республики Казахстан. Основным требованием использования сеточной модели, шаблон которой строился в масштабе 1:7500000, является приведение всех используемых карт к одному масштабу. Информация по климатическим параметрам на с легендой к каждой карте. В качестве примера на рисунке 1 представлена сеточная модель карты «Атмосферная засуха»

Как видно из рисунка, информация по параметру атмосферная засуха представлена в виде изолиний значений числа дней с температурой воздуха выше $30^{\circ} \mathrm{C}$, а нам надо построить матрицу количественных данных для каждого блока сеточной модели по всем восьми выбранным в качестве анализируемых параметров картам. В сеточных моделях вся информация по блоку приписывается в количественной форме центру блока. Таким образом, в случае территориального представления параметра в виде изолиний, потребуется использовать метод интерполяции. Его суть заключается в поиске кратчайшей линии, соединяющей соседние изолинии и проходящей через центр блока. В нашем случае для реализации этого метода использовались ГИС-технологии (ArcGIS и MapInfo Professional 17.0). Последовательное применение этих технологий ко всем 209 блокам сеточной модели по всем восьми картам обеспечило получение матрицы первичной исходной информации, представленной в таблице 1. 


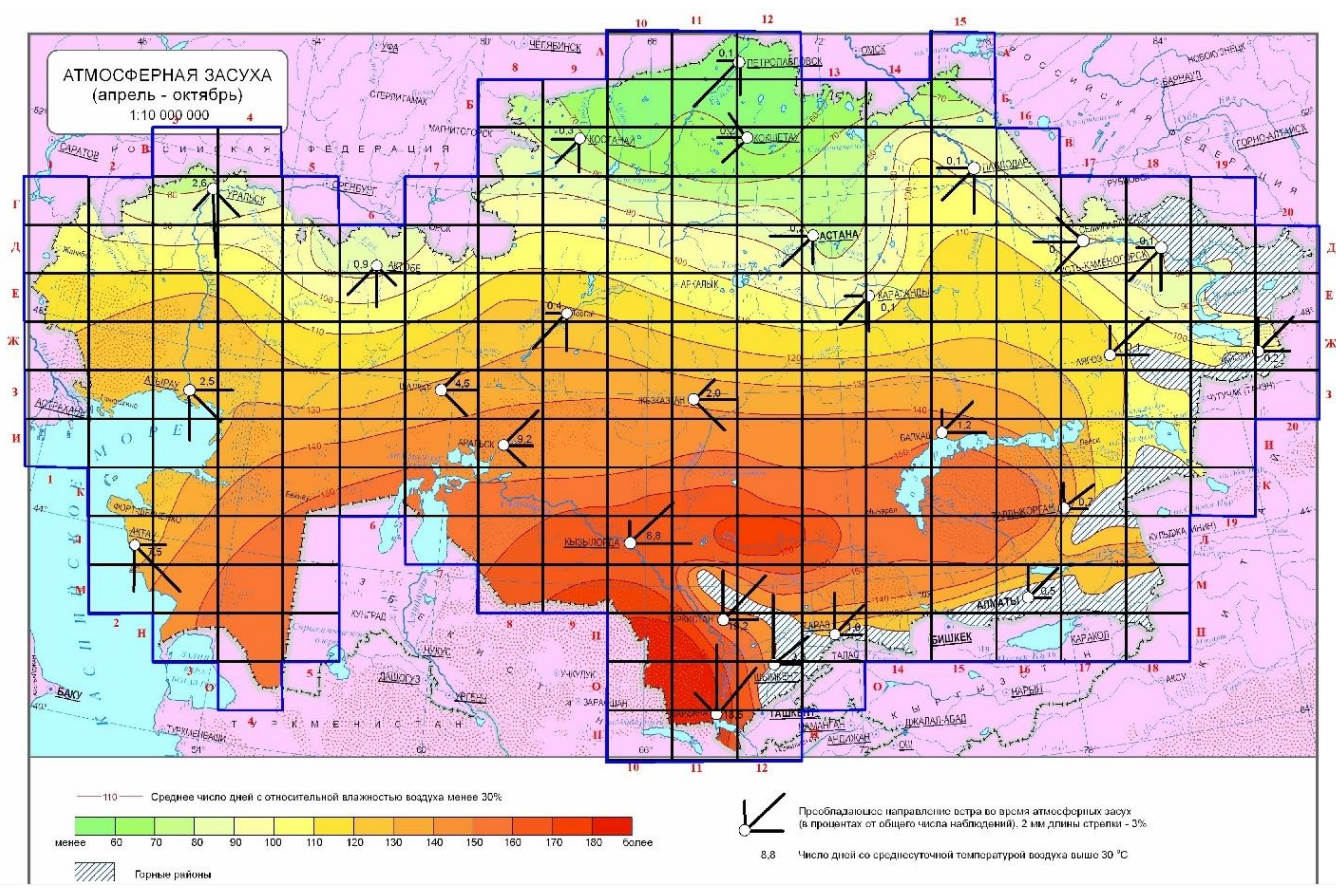

Рис. 1. Сеточная модель карты «Атмосферная засуха (апрель-октябрь» из [10].

Таблица 1. Выборка из полной матрицы исходных количественных данных, полученных на основе сеточных моделей

\begin{tabular}{|c|c|c|c|c|c|c|c|c|c|}
\hline № блока & $\begin{array}{c}\text { Обоз } \\
\text { начение } \\
\text { блока }\end{array}$ & $\begin{array}{c}\text { Сумма } \\
\text { активных } \\
\text { температур } \\
\text { (больше } \\
\left.\mathbf{1 0}^{\circ} \mathrm{C}\right)\end{array}$ & $\begin{array}{c}\text { Продолж. } \\
\text { периода со } \\
\text { среднесут. } \\
\text { темпер. возд. } \\
\text { выше } 10 \text { C, в } \\
\text { днях } \\
\end{array}$ & $\begin{array}{l}\text { Осадки } \\
\text { за } \\
\text { теплый } \\
\text { период } \\
\text { (в мм) }\end{array}$ & $\begin{array}{c}\text { Атмо } \\
\text { сферная } \\
\text { засуха, } \\
\text { дней }\end{array}$ & $\begin{array}{c}\text { Пыль } \\
\text { ные } \\
\text { бури, } \\
\text { дни }\end{array}$ & $\begin{array}{c}\text { Осадки. } \\
\text { Год, } \\
\text { мм/год }\end{array}$ & $\begin{array}{c}\text { Солнеч } \\
\text { ное } \\
\text { сияние } \\
\text { час/год. }\end{array}$ & $\begin{array}{c}\text { Ско } \\
\text { рость } \\
\text { ветра }\end{array}$ \\
\hline & & CAT & ПрТП & ОсТП & AT3 & ПБ & OcГ & $\mathbf{C C}$ & СкВ \\
\hline 1 & 2 & 3 & 4 & 5 & 6 & 7 & 8 & 9 & 10 \\
\hline 1 & A-10 & 2218,44 & 135,00 & 260,59 & 60,00 & 5 & 352,46 & 2188,00 & 2 \\
\hline 2 & A-11 & 2195,51 & 127,94 & 263,11 & 59,90 & 8 & 352,67 & 2164,00 & 2 \\
\hline 5 & B-8 & 2298,47 & 145,52 & 265,22 & 79,43 & 11 & 346,74 & 2253,00 & 5 \\
\hline 6 & B-9 & 2346,49 & 142,19 & 250,96 & 68,04 & 14 & 334,39 & 2233,00 & 5 \\
\hline 12 & B-15 & 2169,29 & 139,60 & 216,90 & 73,07 & 15 & 292,95 & 2457,00 & 1 \\
\hline 13 & $\mathrm{~V}-3$ & 2852,67 & 148,72 & 204,10 & 71,76 & 1 & 358,98 & 2345,00 & 4 \\
\hline 14 & $\mathrm{~V}-4$ & 2824,66 & 148,51 & 216,94 & 76,26 & 2 & 357,67 & 2329,00 & 4 \\
\hline 23 & $\mathrm{~V}-16$ & 2454,16 & 140,57 & 230,17 & 82,79 & 5 & 293,93 & 2420,00 & 7 \\
\hline 24 & G-1 & 3018,83 & 161,91 & 186,63 & 98,32 & 2 & 285,02 & 2453,00 & 3 \\
\hline 37 & G-15 & 2592,65 & 144,76 & 200,65 & 104,38 & 9 & 277,38 & 2523,00 & 2 \\
\hline 38 & G-16 & 2614,05 & 142,44 & 194,48 & 91,58 & 8 & 238,18 & 2452,00 & 1 \\
\hline 39 & G-17 & 2623,27 & 140,37 & 200,22 & 81,83 & 9 & 271,84 & 2452,00 & 6 \\
\hline 40 & G-18 & 2171,98 & 134,65 & 271,90 & 73,49 & 5 & 437,89 & 2443,00 & 6 \\
\hline 41 & G-19 & 1982,47 & 146,68 & 280,96 & 76,97 & 5 & 503,71 & 2429,00 & 6 \\
\hline 42 & D-1 & 3178,21 & 169,53 & 164,68 & 106,55 & 8 & 269,72 & 2495,00 & 4 \\
\hline 43 & D-2 & 3145,93 & 166,61 & 159,97 & 103,12 & 9 & 267,69 & 2495,00 & 4 \\
\hline 60 & D-19 & 2576,43 & 133,95 & 325,25 & 78,80 & 10 & 516,69 & 2470,00 & 2 \\
\hline 61 & D-20 & 2720,96 & 109,56 & 302,00 & 89,77 & 12 & 515,95 & 2467,00 & 2 \\
\hline 62 & E-1 & 3378,74 & 172,54 & 149,51 & 114,70 & 10 & 235,70 & 2519,00 & 4 \\
\hline 140 & I-19 & 3418,89 & 152,36 & 198,53 & 108,06 & 2 & 388,06 & 2698,00 & 2 \\
\hline 156 & K-17 & 3236,41 & 168,53 & 277,85 & 120,90 & 22 & 425,07 & 2694,00 & 6 \\
\hline 157 & K-18 & 2422,88 & 138,07 & 315,48 & 113,53 & 10 & 439,70 & 2697,00 & 3 \\
\hline 187 & M-16 & 3629,91 & 167,46 & 300,07 & 127,00 & 10 & 429,95 & 2366,00 & 5 \\
\hline 188 & M-17 & 3472,40 & 166,49 & 304,55 & 129,37 & 10 & 423,79 & 2369,00 & 4 \\
\hline 189 & M-18 & 2775,00 & 144,71 & 318,19 & 128,34 & 10 & 389,58 & 2374,00 & 4 \\
\hline
\end{tabular}


Продолжение таблицы 1.

\begin{tabular}{|c|c|c|c|c|c|c|c|c|c|}
\hline 1 & 2 & 3 & 4 & 5 & 6 & 7 & 8 & 9 & 10 \\
\hline 190 & $\mathrm{~N}-3$ & 4281,78 & 197,29 & 75,11 & 149,50 & 9 & 150,24 & 2599,00 & 3 \\
\hline 197 & $\mathrm{~N}-14$ & 3365,59 & 182,96 & 216,53 & 125,42 & 25 & 429,47 & 2731,00 & 6 \\
\hline 198 & $\mathrm{~N}-15$ & 3343,81 & 141,69 & 203,55 & 124,36 & 14 & 512,93 & 2393,00 & 6 \\
\hline 199 & $\mathrm{~N}-16$ & 2845,76 & 135,45 & 529,47 & 124,29 & 2 & 498,78 & 2146,00 & 7 \\
\hline 200 & $\mathrm{~N}-17$ & 2789,61 & 134,22 & 526,98 & 126,59 & 1 & 501,88 & 2149,00 & 6 \\
\hline 201 & $\mathrm{~N}-18$ & 2435,98 & 133,49 & 387,35 & 124,54 & 1 & 434,01 & 2182,00 & 4 \\
\hline 202 & $\mathrm{O}-4$ & 4281,60 & 197,95 & 70,44 & 154,87 & 2 & 135,83 & 2730,00 & 5 \\
\hline 203 & $\mathrm{O}-10$ & 4309,90 & 203,65 & 52,47 & 161,87 & 10 & 99,96 & 3066,00 & 6 \\
\hline 204 & $\mathrm{O}-11$ & 4459,87 & 209,49 & 70,15 & 164,53 & 15 & 146,36 & 3035,00 & 5 \\
\hline 205 & $\mathrm{O}-12$ & 4086,95 & 206,93 & 192,07 & 148,36 & 20 & 492,25 & 2889,00 & 5 \\
\hline 206 & $\mathrm{O}-13$ & 2800,08 & 172,61 & 427,10 & 122,08 & 24 & 501,71 & 2760,00 & 5 \\
\hline 207 & $\mathrm{P}-10$ & 4408,55 & 209,52 & 69,00 & 176,95 & 22 & 100,63 & 3050,00 & 4 \\
\hline 208 & $\mathrm{P}-11$ & 4482,54 & 208,32 & 77,00 & 184,06 & 19 & 193,18 & 2993,00 & 5 \\
\hline 209 & $\mathrm{P}-12$ & 4073,28 & 213,29 & 174,61 & 150,79 & 11 & 455,73 & 3000,00 & 5 \\
\hline
\end{tabular}

В полученной матрице исходной количественной информации каждый столбец, содержащий один из 8 выбранных параметров (соответственно одной из 8 карт), имеет разные единицы измерения. Для перевода полученных исходных количественных значений в единую систему сопоставимых данных требует применения экспертного метода построения оценочных шкал, объективность которых подтверждается независимыми исследованиями по анализу полного диапазона изменений каждого из выбранных параметров. Это самая сложная и требующая большого времени и усилий задача по поиску независимых источников информации по динамике изучаемых параметров. Результаты обоснования оценочных шкал представлены в следующем разделе статьи.

Рассмотрим теперь способ построения общего вида модели расчета интегральной (синонимы - суммарной, комплексной) целевой функции агроклиматического потенциала благоприятности возделывания яровой пшеницы с использованием метода целевой функции. Суть метода изложена в монографии авторов [13] и коротко сводится к следующему. За вид целевой функции $(Ц \Phi)$, определяющей величину агроклиматического потенциала, в соответствии с рекомендациями Р. Пэнтла [14] принимаем уравнение множественной линейной регрессии.

$$
Ц \Phi=a_{1} \cdot f_{1}+a_{2} \cdot f_{2}+\ldots+a_{n} \cdot f_{n},
$$

Как отмечено в [14], эта запись справедлива для расчета как частных целевых функций (ЧЦФ), так и для интегральной целевой функции (ИЦФ).

$$
\text { ЧЦФ } \Phi_{j}=a_{1 j} \cdot f_{1 j}+a_{2 j} \cdot f_{2 j}+\ldots+a_{n j} \cdot f_{n j},
$$

где $f_{i j}$ представляет собой $i$-тый измеряемый фактор (отдельный измеряемый параметр) из $n$ параметров, входящих в группу схожих параметров) в каждой $j$-той группе после приведения их к одинаковой единице измерения параметров во всех группах (частных целевых функциях);

$a_{i j}$ отражает роль $i$-того параметра в $j$-той группе, причем сумма $n$ значений $a_{i j}$ в каждой $j$-той группе приравнивается к 1 ;

Для интегральной целевой функции ИЦФ вместо $f_{i}$ в уравнение (1) подставляются $Ч Ц \Phi_{j}$, а замена $a_{i j}$ на $b_{i}$ означает, что весовые коэффициенты отражают теперь значимость этой группы в ИЦФ. Для расчета значений интегральной целевой функции получим уравнение (3):

$$
\text { ИЦФ }=b_{1} \cdot Ч Ц \Phi_{1}+b_{2} \cdot Ч Ц \Phi_{2}+\ldots+b_{n} \cdot Ч Ц \Phi_{n}
$$

Поскольку уравнение (3) используется для расчета интегральной целевой функции во всех блоках сеточной модели, оно может дать представление о территориальной дифференциации агроклиматического потенциала уровня благоприятности возделывания яровой пшеницы, т.е. уравнение (3) является формальной записью достижения поставленной цели исследования.

Результаты исследования. Первым результатом исследования является конкретизация вида частных и интегральной целевых функций. Наш опыт обоснования вида частных и интегральных функций в сфере геоэкологии и туризма представлен в работах $[15,17-19]$. В соответствии с тематикой выбранных для анализа карт агроклиматических и чисто 
климатических параметров несложно сформировать 2 группы параметров, отражающих агроклиматические (характеризующие теплый период года со среднесуточной температурой более $10^{\circ} \mathrm{C}-\mathrm{CAT}$, ПрТП, ОсТП и Ат3) и климатические параметры (ПБ, ОсГ, СС, СкВ). Таким образом, мы будем выделять только 2 частные целевые функции - ЧЦФ Агро И ЧЦФ Кли. Весовые коэффициенты при климатических и агроклиматических параметрах в этих частных целевых функциях выбраны в соответствии с оценкой их ролей для возделывания яровой пшеницы в используемом в работе списке обзорных публикаций [7-9, 11,12, 21-24].

При выполнении условия приравнивания суммы нагрузок в уравнениях для целевых функций 1 получим следующую систему уравнений для расчетов значений частных и суммарной целевых функций для каждого блока сеточной модели:

$$
\begin{gathered}
\text { ЧФ } \Phi_{\text {Агро }}=0,4 \cdot C A T+0,25 \cdot \Pi p T \Pi+0,6 \cdot \text { ОсТП }-0,25 \cdot A m 3 \\
\text { } \Phi_{\text {Клим }}=0,4 \cdot \mathrm{CC}+0,4 \cdot \mathrm{C \kappa} \mathrm{B}+0,5 \cdot \text { ОсГ }-0,3 \cdot П Б \\
\text { ИЦФ } \Phi_{\text {АгроКлим }}=0,6 \cdot Ч Ц \Phi_{\text {Агро }}+0,4 \cdot Ч Ц \Phi_{\text {Клим }}
\end{gathered}
$$

Эту систему следует рассматривать как первый опыт попыток построения моделей территориальной дифференциации агроклиматического потенциала на примере условий возделывания яровой пшеницы в Казахстане.

Вторым результатом исследований, обеспечивающим возможность выполнения расчетов значений частных и интегральной целевых функций для анализа территориальной дифференциации агроклиматического потенциала территории Казахстана, является перевод полученных по картам сеточных моделей первичных количественных значений параметров с разными единицами измерения в матрицу сопоставимых значений с позиций соответствия их уровню благоприятности для возделывания яровой пшеницы. Эта задача решается на основе экспертных оценочных шкал, построенных на независимых видах исследований влияния разных диапазонов климатических и агроклиматических параметров на успешность возделывания яровой пшеницы.

Мы уже имели опыт построения оценочных шкал в примерах по комплексным оценкам благоприятности климата для туризма, качества жизни населения, интенсивности процессов опустынивания, который показал четкую зависимость вида оценочных шкал не только от области исследования, но и конкретного объекта. И если в проблемах качества жизни и туризме мы анализировали благоприятность разных диапазонов климатических условий по отношению к человеку, а потому там имелось достаточное количество независимых источников по медикобиологическим исследованиям состояния человека, то в агроклиматических аспектах приходится рассматривать конкретные виды сельскохозяйственных растений, которые весьма сильно отличаются по требованиям к природным условиям.

Поскольку одной из самых распространенных возделываемых культур в Казахстане является яровая пшеница, в качестве объекта исследования мы выбрали именно её. В [9] отмечается, что яровой пшенице свойственна стрессоустойчивость, она способна выжить в относительно засушливых условиях, однако наличие достаточного количества влаги в начале вегетации - обязательное условие. Потому яровая пшеница обычно выращивается там, где идут весенние и ранние летние дожди.

Представление о логике построения оценочных шкал климатических параметров можно составить по нашим предыдущим работам [13-18]. Агроклиматические параметры в качестве параметров целевых функций мы рассматриваем впервые, поэтому остановимся подробнее на обосновании их оценочных шкал.

В статье [7] отмечается: «Агроклиматические ресурсы - это свойства климата, обеспечивающие возможности сельскохозяйственного производства. Они характеризуются: продолжительностью периода со среднесуточной температурой выше $+10^{\circ} \mathrm{C}$; суммой температур за этот период; соотношением тепла и влаги; запасами влаги, создаваемыми в данный период снежным покровом.

Разные регионы нашей страны обладают разными агроклиматическими ресурсами, но в целом на территории Казахстана солнечного тепла достаточно для созревания многих сельскохозяйственных культур. При среднесуточной температуре выше $+10^{\circ} \mathrm{C}$ его суммарное количество значительно колеблется: на севере в пределах $2000-2100^{\circ} \mathrm{C}$, а на юге в диапазоне $4600-4800^{\circ} \mathrm{C}$.

В северной части республики период, когда среднесуточная температура превышает $+10^{\circ} \mathrm{C}$, вегетационный период длится 130-135 дней. Здесь агроклиматические ресурсы подходят для выращивания яровой пшеницы, льна, овощей, фруктов и бахчевых. В центральной части 
Казахстана климат относительно сухой. Ресурсы тепла - $2400^{\circ}-2800^{\circ} \mathrm{C}$. Количество дней, когда средняя температура поднимается выше $+10^{\circ} \mathrm{C}$, составляет 150-160. Здесь можно выращивать зерновые культуры, подсолнечник, гречиху и картофель. На юге республики вегетационный период длится немногим более 180 дней. Изобилие солнечного тепла позволяет выращивать здесь такие орошаемые культуры, как рис, хлопчатник, табак, виноград, сахарную свеклу и др.».

Таким образом, в этой работе представлены реальные диапазоны агроклиматических ресурсов по территории Казахстана. Эти величины мы использовали для определения полных диапазонов параметров. Однако их было бы достаточно, если бы мы были уверены в линейном характере оценочных шкал. Однако наличие сведений об оптимальных значениях параметров возделывания яровой пшеницы являются свидетельством их нелинейности. Рассмотрим теперь конкретные агрометеорологические параметры, количественные значения которых были получены на основе сеточных моделей карт.

В первую очередь рассмотрим сумму активных температур (САТ). Максимальная сумма средних суточных температура воздуха выше $10^{\circ} \mathrm{C}$ по данным сеточной модели «Сумма средних суточных температур воздуха выше $10^{\circ} \mathrm{C} \gg-4508^{\circ} \mathrm{C}$. В статье [21] приводятся данные по оптимальным суммам активных температур (САТ) для отдельных фаз развития яровой пшеницы: за период посев-всходы она равна $100-130^{\circ} \mathrm{C}$ за период от всходов до колошения составляет $800-900^{\circ} \mathrm{C}$, от колошения до созревания $-650-700^{\circ} \mathrm{C}$, что в сумме составит $1730^{\circ} \mathrm{C}$.

В обзорных работах по изменению климата Казахстана отмечался факт минимальной величины САТ порядка $400^{\circ} \mathrm{C}$, когда пшенице не удалось сформировать полноценные зерна, т.е. урожай фактически погиб. С другой стороны, в статье [7] указывается на нежелательность высоких значений САТ, которые определяются температурами вегетационного периода. Там отмечается что яровая пшеница плохо переносит высокие температуры - при $38-40^{\circ} \mathrm{C}$ через 10 17 ч происходит паралич устьиц. Сухие ветра при жаркой погоде усиливают негативное действие высоких температур.

Исходя из приведенных данных, можно сделать вывод, что САТ, так же, как и параметр температуры, не может являться линейной функцией. Но отсутствие более детальных наблюдений вынуждает нас вместо реальной кривой использовать её аппроксимацию в виде двух отрезков прямых линий. Фактически мы будем иметь сплайн из прямых, пересекающихся в точке максимального значения оптимального диапазона САТ, который для удобства расчетов примем за $1750^{\circ} \mathrm{C}$. В качестве начала левой части сплайна примем точку $400^{\circ} \mathrm{C}$, а правой части - $4800^{\circ} \mathrm{C}$ (эта величина указывалась в качестве максимальной для южных регионов). В этом случае для левой части сплайна при переводе в баллы диапазон $1750-400=1350^{\circ} \mathrm{C}$ приравняем 10 баллам. Цена одного балла в этом случае составит $135^{\circ} \mathrm{C}$. Чтобы перевести текущее значение САТ для левой части надо применить формулу (7)

$$
\mathrm{CAT}_{\text {ілев }}(\text { б })=10 б-\left(1750^{\circ} \mathrm{C}-\mathrm{CAT}^{\circ} \mathrm{C}_{\text {ілев }}\right) / 135^{\circ} \mathrm{C} / \sigma
$$

Для правой части длина диапазона составит $4800-1750=3050^{\circ} \mathrm{C}$, т.е. цена одного балла составит $305^{\circ} \mathrm{C}$, а для расчета текущих значений САТ надо будет использовать формулу (8):

$$
\mathrm{CAT}_{\text {i рав }}\left(\text { б) }=10 б-\left(\mathrm{CAT}^{\circ} \mathrm{C}_{\text {i рав }}-1750^{\circ} \mathrm{C}\right) / 305^{\circ} \mathrm{C} / \sigma\right.
$$

В работе [8] указывается также максимальная величина из оптимального диапазона для северных регионов Казахстан продолжительности теплого периода 130-135 дней, а для центральных и южных регионов - 85-115 дней. Для построения шкалы величину 115 дней примем за оптимальную, т.е. присвоим ей 10 баллов. И опять наличие оптимума вынуждает использовать аппроксимацию криволинейной зависимости сплайном. С учетом того, что максимальная продолжительность теплого периода (апрель-октябрь) составляет 215 дней, цена балла для левой части составит 115/10 = 11,5 дней, а правой - (215-115)/10 = 10 дней. Формулы для перерасчета в баллы ПрТП ${ }_{i}$ будут аналогичны формулам (1) и (2) с подстановкой границ диапазонов и цены баллов для ПрТП. После подстановки получим формулы (9) и (10):

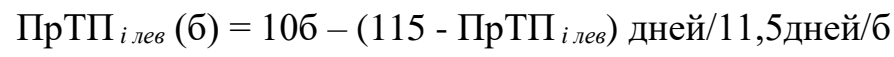

$$
\begin{aligned}
& \Pi_{\text {рТТ }}^{\text {прав }} \text { (б) = } 10 б-\left(П_{\text {рTП }} \text { прав }-115\right) \text { дней/10 дней/б }
\end{aligned}
$$

Осадки теплого периода (ОсТП) также имеют зону оптимума, рассчитанную в [24] как потребность всех этапов развития пшеницы и равную 310 мм. Максимальную величину берем за 1600 мм (зона горного Алтая). и опять имеем сплайн. Для левой части цена 1 балла составит 
31 мм, для правой - 129 мм. Повторяя процедуры, аналогичные приведенным выше, получим формулы (11) и (12):

$$
\begin{aligned}
& \mathrm{OcTП}_{\text {ілев }}\left(\text { б) }=10 б-\left(310-\text { ОсТП }_{\text {ілев }}\right) \text { мм } / 31 \mathrm{мm} / б\right. \\
& \text { ОсТП }_{i \text { прав }}\left(\text { б) }=10 б-\left(\text { ОсТП }_{\text {прав }}-310\right)\right. \text { мм/129 мм/б }
\end{aligned}
$$

Последним из выбранных нами для построения целевых функций параметром является атмосферная засуха (Ат3). Параметр имеет линейную оценочную шкалу, поскольку он характеризует негативное воздействие на возделывание пшеницы, которое не может иметь зоны оптимума. Здесь за 0 баллов принимаем длину всего теплого периода - 215 дней, а за 10 баллов 0 дней, т.е. полное отсутствие засухи. Таким образом, цена одного балла будет равна 21,5 дней.

Следует отметить, что в приведенном обзоре выбранные в качестве климатических параметры рассматриваются как дополнительные, которые отражают оттенки влияния климатических параметров на возделывание яровой пшеницы. Так, например, для возделывания яровой пшеницы большое значение придается осадкам теплого периода, но среднегодовые осадки отражают фактор увлажнения почв, важный в период сева. Точно так же солнечное сияние и оптимальный диапазон скорости ветра отражают оптимальные условия осуществления фотосинтеза. В качестве негативного фактора мы выдели «пыльные бури», поскольку при пыльных бурях сильный ветер выдувает верхние слои почвы, часто с семенами и молодыми растениями, нанося большой вред сельскому хозяйству.

Поскольку все климатические факторы представлены среднегодовыми величинами, для построения их оценочных шкал удобно воспользоваться опытом их обоснования при оценке климатических параметров качества жизни населения [18] с учетом возможной специфики изменения объекта исследования. Как и в [18], параметры СС и ПБ являются линейными с теми же граничными условиями. Параметр «скорость ветра» также можно принять без изменения, т.к. безветрие негативно сказывается на снабжении растений кислородом, а сильный ветер (уже при скоростях более 8 м/сек) вызывает пыльные бури. Шкала перевода годовых осадков в баллы фактически будет повторять шкалу осадков теплого периода, поскольку в описаниях климата Казахстана отсутствуют отельные определения максимального количества осадков для теплого периода.

Третьим результатом исследования являются результаты расчетов значений частных и интегральной целевых функций после подстановки переведенных в баллы первичных исходных параметров, полученных на основе сеточных моделей территории РК в уравнения (46). После подстановки в эти уравнения значений параметров в балльной форме для всех 209 блоков сеточной модели мы получим окончательное решение. Поскольку матрица имеет большие размеры, приведем выборку с разбросом значений по всему диапазону полученных результатов для общего представления о характере дифференциации интегральной целевой функции по территории (таблица 2).

Таблица 2. Выборка из матрицы балльных значений параметров и результатов расчетов частных и суммарной целевых функций

\begin{tabular}{|c|c|c|c|c|c|c|c|c|c|c|c|c|c|c|}
\hline $\begin{array}{c}\text { № } \\
\text { блока }\end{array}$ & $\begin{array}{c}\text { Обозна- } \\
\text { чение } \\
\text { блока }\end{array}$ & САТ & ПрТП & ОсТП & Ат3 & $\begin{array}{c}\text { ЧЦФ } \\
\text { Агро }\end{array}$ & ПБ & ОсГ & СС & СкВ & $\begin{array}{c}\text { ЧЦФ } \\
\text { Клим }\end{array}$ & $\begin{array}{c}\text { ИЦФ } \\
\text { АгроКлим }\end{array}$ \\
\hline 1 & 2 & 3 & 4 & 5 & 6 & 7 & 8 & 9 & 10 & 11 & 12 & 13 \\
\hline 1 & A-10 & 8,46 & 8,00 & 8,41 & 2,79 & 9,73 & 0,23 & 3,16 & 4,89 & 7,5 & 6,47 & 8,43 \\
\hline 2 & A-11 & 8,54 & 8,71 & 8,49 & 2,79 & 9,99 & 0,37 & 3,16 & 4,84 & 7,5 & 6,40 & 8,55 \\
\hline 5 & B-8 & 8,20 & 6,95 & 8,56 & 3,69 & 9,23 & 0,51 & 3,08 & 5,04 & 4 & 5,00 & 7,54 \\
\hline 6 & B-9 & 8,04 & 7,28 & 8,10 & 3,16 & 9,10 & 0,65 & 2,93 & 5,00 & 4 & 4,87 & 7,41 \\
\hline 12 & B-15 & 8,63 & 7,54 & 7,00 & 3,40 & 8,68 & 0,70 & 2,41 & 5,50 & 2,5 & 4,20 & 6,89 \\
\hline 13 & V-3 & 6,38 & 6,63 & 6,58 & 3,34 & 7,33 & 0,05 & 3,24 & 5,25 & 6,5 & 6,30 & 6,92 \\
\hline 14 & V-4 & 6,48 & 6,65 & 7,00 & 3,55 & 7,56 & 0,09 & 3,22 & 5,21 & 6,5 & 6,27 & 7,05 \\
\hline 23 & V-16 & 7,69 & 7,44 & 7,42 & 3,85 & 8,43 & 0,23 & 2,42 & 5,41 & 2,5 & 4,31 & 6,78 \\
\hline 24 & G-1 & 5,84 & 5,31 & 6,02 & 4,57 & 6,13 & 0,09 & 2,31 & 5,49 & 9,5 & 7,12 & 6,53 \\
\hline 37 & G-15 & 7,24 & 7,02 & 6,47 & 4,85 & 7,32 & 0,42 & 2,22 & 5,64 & 7,5 & 6,24 & 6,89 \\
\hline 38 & G-16 & 7,17 & 7,26 & 6,27 & 4,26 & 7,38 & 0,37 & 1,73 & 5,49 & 2,5 & 3,95 & 6,01 \\
\hline 39 & G-17 & 7,14 & 7,46 & 6,46 & 3,81 & 7,64 & 0,42 & 2,15 & 5,49 & 3 & 4,34 & 6,32 \\
\hline 40 & G-18 & 8,62 & 8,04 & 8,77 & 3,42 & 9,86 & 0,23 & 4,22 & 5,47 & 3 & 5,43 & 8,09 \\
\hline 41 & G-19 & 9,24 & 6,83 & 9,06 & 3,58 & 9,95 & 0,23 & 5,05 & 5,43 & 3 & 5,83 & 8,30 \\
\hline
\end{tabular}


Продолжение таблицы 2.

\begin{tabular}{|c|c|c|c|c|c|c|c|c|c|c|c|c|}
\hline 1 & 2 & 3 & 4 & 5 & 6 & 7 & 8 & 9 & 10 & 11 & 12 & 13 \\
\hline 42 & D-1 & 5,32 & 4,55 & 5,31 & 4,96 & 5,21 & 0,37 & 2,12 & 5,58 & 6,5 & 5,78 & 5,44 \\
\hline 43 & D-2 & 5,42 & 4,84 & 5,16 & 4,80 & 5,28 & 0,42 & 2,10 & 5,58 & 6,5 & 5,76 & 5,47 \\
\hline 60 & D-19 & 7,29 & 8,11 & 9,88 & 3,67 & 9,96 & 0,47 & 5,21 & 5,53 & 7,5 & 7,68 & 9,04 \\
\hline 61 & D-20 & 6,82 & 9,46 & 9,74 & 4,18 & 9,89 & 0,56 & 5,20 & 5,52 & 7,5 & 7,64 & 8,99 \\
\hline 62 & E-1 & 4,66 & 4,25 & 4,82 & 5,33 & 4,49 & 0,47 & 1,70 & 5,64 & 6,5 & 5,56 & 4,92 \\
\hline 140 & I-19 & 4,53 & 6,26 & 6,40 & 5,03 & 5,96 & 0,09 & 3,60 & 6,04 & 7,5 & 7,19 & 6,45 \\
\hline 156 & K-17 & 5,13 & 4,65 & 8,96 & 5,62 & 7,18 & 1,02 & 4,06 & 6,03 & 3 & 5,34 & 6,44 \\
\hline 157 & K-18 & 7,79 & 7,69 & 10,18 & 5,28 & 9,83 & 0,47 & 4,25 & 6,03 & 9,5 & 8,20 & 9,17 \\
\hline 187 & M-16 & 3,84 & 4,75 & 9,68 & 5,91 & 7,05 & 0,47 & 4,12 & 5,29 & 4 & 5,64 & 6,49 \\
\hline 188 & M-17 & 4,35 & 4,85 & 9,82 & 6,02 & 7,34 & 0,47 & 4,05 & 5,30 & 6,5 & 6,60 & 7,05 \\
\hline 189 & M-18 & 6,64 & 7,03 & 10,26 & 5,97 & 9,08 & 0,47 & 3,62 & 5,31 & 6,5 & 6,39 & 8,01 \\
\hline 190 & N-3 & 1,70 & 1,77 & 2,42 & 6,95 & 0,84 & 0,42 & 0,63 & 5,81 & 9,5 & 6,31 & 3,03 \\
\hline 197 & N-14 & 4,70 & 3,20 & 6,98 & 5,83 & 5,41 & 1,16 & 4,12 & 6,11 & 3 & 5,35 & 5,39 \\
\hline 198 & N-15 & 4,77 & 7,33 & 6,57 & 5,78 & 6,24 & 0,65 & 5,16 & 5,35 & 3 & 5,73 & 6,03 \\
\hline 199 & N-16 & 6,41 & 7,96 & 1,74 & 5,78 & 4,15 & 0,09 & 4,98 & 4,80 & 2,5 & 5,38 & 4,64 \\
\hline 200 & N-17 & 6,59 & 8,08 & 1,73 & 5,89 & 4,22 & 0,05 & 5,02 & 4,81 & 3 & 5,62 & 4,78 \\
\hline 201 & N-18 & 7,75 & 8,15 & 1,27 & 5,79 & 4,45 & 0,05 & 4,18 & 4,88 & 6,5 & 6,63 & 5,32 \\
\hline 202 & O-4 & 1,70 & 1,71 & 2,27 & 7,20 & 0,67 & 0,09 & 0,45 & 6,11 & 4 & 4,24 & 2,10 \\
\hline 203 & O-10 & 1,61 & 1,14 & 1,69 & 7,53 & 0,06 & 0,47 & 0,00 & 6,86 & 3 & 3,80 & 1,56 \\
\hline 204 & O-11 & 1,12 & 0,55 & 2,26 & 7,65 & 0,03 & 0,70 & 0,58 & 6,79 & 4 & 4,40 & 1,78 \\
\hline 205 & O-12 & 2,34 & 0,81 & 6,20 & 6,90 & 3,13 & 0,93 & 4,90 & 6,46 & 4 & 6,36 & 4,42 \\
\hline 206 & O-13 & 6,56 & 4,24 & 1,40 & 5,68 & 3,10 & 1,12 & 5,02 & 6,17 & 4 & 6,25 & 4,36 \\
\hline 207 & P-10 & 1,28 & 0,55 & 2,23 & 7,69 & 0,06 & 1,02 & 0,01 & 6,82 & 6,5 & 5,03 & 2,05 \\
\hline 208 & P-11 & 1,04 & 0,67 & 2,48 & 8,00 & 0,07 & 0,88 & 1,16 & 6,70 & 4 & 4,60 & 1,88 \\
\hline 209 & P-12 & 2,38 & 0,17 & 5,63 & 6,56 & 2,74 & 0,51 & 4,45 & 6,71 & 4 & 6,35 & 4,18 \\
\hline
\end{tabular}

Обсуждение результатов. Для удобства восприятия результатов моделирования агроклиматического потенциала интегральной целевой функцией (последний столбец таблицы 2) была построена классификация для отображения каждого класса определенным цветом. Шкала разбалловки рассчитанных значений целевых функций принята традиционной: диапазон в 10 баллов разбивается по уровням благоприятности условий возделывания яровой пшеницы на 5 классов по 2 балла в каждом:

\begin{tabular}{|c|c|c|c|c|}
\hline Номер & \multicolumn{2}{|c|}{ Границы классов в баллах } & \multirow{2}{*}{ Характеристика класса } & Условное обозначение \\
\cline { 2 - 3 } класса & от & до & наиболее благоприятный & \\
\hline 5 & 8 & 10 & благоприятный & \\
\hline 4 & 6 & 8 & средней благоприятности & \\
\hline 3 & 4 & 6 & малоблагоприятный & \\
\hline 2 & 2 & 4 & неблагоприятный & \\
\hline 1 & 0 & 2 &
\end{tabular}

Визуальное представление конечного результата - интегральной целевой функции агроклиматического потенциала возделывания яровой пшеницы в Казахстане для всех блоков сеточной модели можно видеть на рисунке 2.

Схема распределения значений интегральной целевой функции по территории РК полностью соответствует приведенной в используемых при работе статьях по возделыванию яровой пшеницы. Таким образом, сферу применения модели целевой функции можно распространить на агроклиматологию. В принципе, по приведенной схеме можно построить модели благоприятности возделывания любой культуры по агроклиматическим параметрам. Однако для каждого из них потребуется анализ литературных или специальных источников для выявления зон оптимальных значений исследуемых параметров, а также полного диапазона изменения агроклиматических параметров при возделывании выбранной для оценки культуры, т.е. для каждой культуры потребуется обоснование оценочных шкал для перевода полученной с помощью сеточных моделей первичной количественной информации с разными единицами измерения в баллы.

Перевод в баллы делает сопоставимыми все параметры и позволяет полнее использовать идею Р. Пэнтла о роли коэффициентов при параметрах в уравнении целевой функции. Теперь они отражают только вклад этого параметра в целевую функцию. Балльная оценка и расширение полного диапазона параметров снимают противоречие с отрицательными 
значениями параметров. Расширение диапазона значений параметра можно провести на отрицательную область оси параметра при положительных значениях на оси баллов. Этот прием также более четко реализует идею Р. Пэнтла о целевой нагрузке знаков коэффициентов значимости: только при положительных значениях параметра отрицательный знак коэффициента значимости будет отражать его целевое назначение - указывать, что рост значений этого параметра будет уменьшать значение целевой функции.

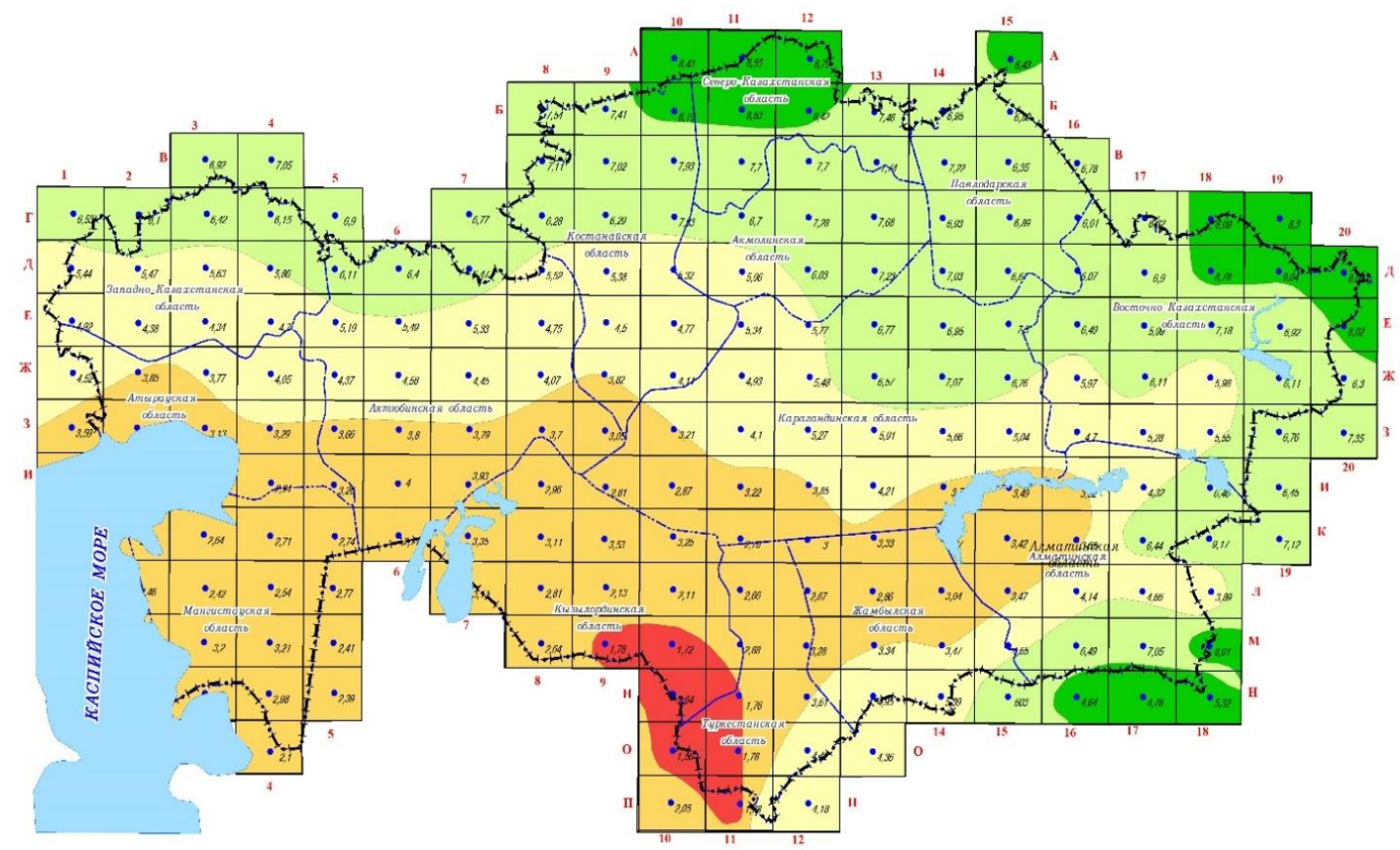

Рис. 2. Территориальная дифференцииачия агроклиматического потенцииала по уровню благоприятности климатических условий для воздельввания яровой пшеницьь

Выводы. Модель целевой функции является универсальным методом построения комплексных оценок самой разной направленности в самых разных сферах исследования.

Мощным подспорьем при получении исходной информации являются разнообразные карты, при этом методом преобразования картографической информации в количественную является построение сеточных моделей территории, в которых весь набор картографической информации в пределах блока сеточной модели привязывается к центру блока.

Обязательным условием построения шаблона сеточной модели является равенство всех блоков по площади и прямоугольные координаты для выполнения этого условия. Процедуры снятия картографической информации в блоке могут быть самыми разными в зависимости от типа информации на картах - площади контуров, длина линейных объектов, количество точечных источников, применение метода интерполяции в случае представления информации в виде изолиний.

Развитие методов ГИС позволяет надеяться на их внедрение в сферу получения первичной количественной информации из картографической.

И еще одно замечание - комплексную оценку агроклиматического потенциала можно расширить введением других параметров - качество земельных ресурсов и даже применение прогрессивных аграрных технологий. Пример этого можно видеть в работе [25] с многозначительным заголовком: «Засуха засухой, но агротехнологии не стоят на месте». В статье не только предлагаются традиционные агротехнологии типа правильных и четких действий на каждом этапе вегетации растений, использование засухоустойчивых семян, но и сообщается о разработке препаратов, развивающих корневую систему растений для обеспечения возможности получать влагу с глубин более 1,5 м.

При этом следует всегда помнить - самая сложная и трудоемкая часть построения моделей целевой функции - это обоснование оценочных шкал, причем обязательно на независимых источниках. 


\section{ЛИТЕРАТУРА}

1. Степанищева К. (2017). Агроклиматические ресурсы - это что такое? Retrieved from https://www.syl.ru/article/299791/agroklimaticheskie-resursyi-eto-chto-takoe

2. Чирков Ю.И. (1979). Агрометеорология. Л., Гидрометиздат

3. Станис Е.В., Макарова М.Г. (2008) Комплексная оценка природных и производственных потенииалов территорий. Москва, М.: РУДН.

4. Исаев А.А. (1989). Прикладная климатология. Москва, М.: МГУ

5. Шашко Д.И. (1967). Агроклиматическое районирование СССР. Москва, М.: Колос

6. География Казахстана (2019). География Казахстана. Retrieved from https://ru.wikipedia.org/wiki/\%D0\%93\%D0\%B5\%D0\%BE\%D0\%B3\%D1\%80\%D0\%B0\%D1\%84\%D0\%B8\%D $1 \% 8$ F_\%D0\%9A\%D0\%B0\%D0\%B7\%D0\%B0\%D1\%85\%D1\%81\%D1\%82\%D0\%B0\%D0\%BD\%D0\%B0

7. География Казахстана (2021). Агроклиматические ресурсы. Получено из https://moxnpn.ru/kazakhstan/56-agroklimaticheskie-resursy.html

8. Байшоланова С.С. (Ред.). (2017). Агроклиматические ресурсы Акмолинской области: научноприкладной справочник. ТОО «Институт географии» МОН РК, Астана.

9. Яровая пшеница. (2021). Retrieved from https://alchemyka.kz/kulturyi/yarovaya-pshenicza.html

10. Медеу А.Р. (Ред.). (2006). Нацииональный Атлас Республики Казахстан. Том І. Природные условия и ресурсы. Алматы.

11. Основные климатические факторы, необходимые для жизни растений. (2018). Retrieved from https://collectedpapers.com.ua/ru/agroclimatology/osnovni-klimatichni-faktorii-neobhidni-dlya-zhittya-roslin

12. Погодные факторы урожая. Тепло. (2021). Retrieved from http://www.speckniga.ru/rastenievodstvo/pogoda-i-pole/pogodnye-faktory-urozhaya-teplo.html

13. Павличенко Л.М., Актымбаева А.С. (2020). Многомерная модель целевой функции как инструмент геоэкологических исследований. Алматы: Қазақ университеті.

14. Пэнтл Р. (1979). Методы системного анализа окружающей среды. Москва, М.: Мир.

15. Pavlichenko L., Shakirova K. (2019). "Territorial differentiation of tourist-recreational potential of the Almaty region," International Academy Journal Web of Scholar, 5(35), 3 - 8. Retrieved from https://doi.org/10.31435/rsglobal_wos/31052019/6498

16. Павличенко Л.М., Джаксыбаева А.Б., Имангалиева А.К. (2019). “ Опыт выявления и интерпретации факторов антропогенного воздействия на растительность Мангистауской области,” Вестник КазГАСА, 2, 225-237.

17. Pavlichenko L.M., Yespolayeva A.R., Aktymbayeva A.S., Jones H., Yesimsiitova Z.B. (2019). "Summarized Assessment of the role Oil and Gas Complex Mangystau Region in Pollution Ground Water," WSEAS Transactions On Environment And Development, 15, 438-446. E-ISSN: 1790-5079

18. Павличенко Л.М., Есильбаева Н.М., Имангалиева А.К., Рысмагамбетова А.А. (2020), “К проблеме дифференциации климатических параметров качества жизни населения,” Вестник КазГАСА, 2, 239-254.

19. Pavlichenko L.M., Yespolayeva A.P., Aktymbayeva A.S., Jones H. (2021). "Estimation of the accuracy of inverse problem solution of complex generalized environmental estimation based on cartographic information," Вестник КазНУ. Серия географическая, 1, 61-79.

20. Джеймс Кук, Роджер Фесет Дж. (2018). Влияние температуры на развитие пиеницы. Retrieved from https://www.agronom.com.ua/vlyyanye-temperatury-na-razvytye-pshenytsy/

21. Сельское хозяйство. (2021). Яровая пшеница. https://universityagro.ru/растениеводство/яровая-пшеница/

22. Жемпиисов Ш.С. (2021). Влияние сроков и норм высева на урожайность яровой пшеницы. Retrieved from http://www.rusnauka.com/6_PNI_2014/Agricole/3_159869.doc.htm\#: :text=\%D0\%98\%D0\%B7\%20\%D0\%BE\%D 0\%B1\%D1\%89\%D0\%B5\%D0\%B3\%D0\%BE\%20\%D0\%BA\%D0\%BE\%D0\%BB\%D0\%B8\%D1\%87\%D0\%B5 $\% \mathrm{D} 1 \% 81 \% \mathrm{D} 1 \% 82 \% \mathrm{D} 0 \% \mathrm{~B} 2 \% \mathrm{D} 0 \% \mathrm{~B} 0 \% 20 \% \mathrm{D} 0 \% \mathrm{BE} \% \mathrm{D} 1 \% 81 \% \mathrm{D} 0 \% \mathrm{~B} 0 \% \mathrm{D} 0 \% \mathrm{~B} 4 \% \mathrm{D} 0 \% \mathrm{BA} \% \mathrm{D} 0 \% \mathrm{BE} \% \mathrm{D} 0 \% \mathrm{~B}$ 2\%20\%D0\%BF\%D0\%BE,\%D0\%BF\%D1\%88\%D0\%B5\%D0\%BD\%D0\%B8\%D1\%86\%D1\%8B\%20\%D0\%B4\% D0\%BE\%D1\%81\%D1\%82\%D0

23. Газета "КазахЗерно.kz". (2010). Казахстан: Засуха от «А» до «Я». Retrieved from https://kazakhzerno.net/14814-kazakhstan-zasukha-ot-a-do-ya/

24. Пыльные бури. (2018). Retrieved from https://collectedpapers.com.ua/ru/agroclimatology/pilovi-buri

25. Засуха засухой, но агротехнологии не стоят на месте. (2020). Retrieved from https://alemagro.com/article/novosti/zasuha-zasuhoy-no-agrotehnologii-ne-stoyat-na 